\title{
1 GestaltMatcher: Overcoming the limits of rare disease \\ 2 matching using facial phenotypic descriptors
}

3 Tzung-Chien $\mathrm{Hsieh}^{1,+}$, Aviram Bar-Haim²,+, Shahida Moosa ${ }^{3}$, Nadja Ehmke ${ }^{4}$, Karen

4 W. Gripp ${ }^{5}$, Jean Tori Pantel ${ }^{1,4}$, Magdalena Danyel ${ }^{4,6}$, Martin Atta Mensah ${ }^{4,7}$, Denise

5 Horn $^{4}$, Stanislav Rosnev ${ }^{4}$, Nicole Fleischer ${ }^{2}$, Guilherme Bonini $^{2}$, Alexander Hustinx ${ }^{1}$,

6 Alexander Schmid ${ }^{1}$, Alexej Knaus ${ }^{1}$, Behnam Javanmardi ${ }^{1}$, Hannah Klinkhammer ${ }^{1,8}$,

7 Hellen Lesmann ${ }^{1}$, Sugirthan Sivalingam ${ }^{1,8,9}$, Tom Kamphans ${ }^{10}$, Wolfgang

8 Meiswinkel ${ }^{10}$, Frédéric Ebstein ${ }^{11}$, Elke Krüger ${ }^{11}$, Sébastien Küry ${ }^{12,13}$, Stéphane

9 Bézieau ${ }^{12,13}$, Axel Schmidt ${ }^{14}$, Sophia Peters ${ }^{14}$, Hartmut Engels ${ }^{14}$, Elisabeth Mangold ${ }^{14}$,

10 Martina Kreiß ${ }^{14}$, Kirsten Cremer ${ }^{14}$, Claudia Perne ${ }^{14}$, Regina C. Betz ${ }^{14}$, Tim

11 Bender ${ }^{14,15}$, Kathrin Grundmann-Hauser ${ }^{16}$, Tobias B. Haack ${ }^{16}$, Matias Wagner ${ }^{17,18}$,

12 Theresa Brunet ${ }^{17}$, Heidi Beate Bentzen ${ }^{19}$, Luisa Averdunk ${ }^{20}$, Kimberly Christine

13 Coetzer ${ }^{3}$, Gholson J. Lyon ${ }^{21,22}$, Malte Spielmann ${ }^{23}$, Christian Schaaf ${ }^{24}$, Stefan

14 Mundlos $^{4}$, Markus M. Nöthen ${ }^{14}$, Peter Krawitz ${ }^{1, *}$

${ }^{1}$ Institute for Genomic Statistics and Bioinformatics, University Hospital Bonn,

17 Rheinische Friedrich-Wilhelms-Universität Bonn, Bonn, Germany;

${ }^{2}$ FDNA Inc., Boston, MA, United States;

$19{ }^{3}$ Division of Molecular Biology and Human Genetics, Stellenbosch University and

20 Medical Genetics, Tygerberg Hospital, Tygerberg, South Africa;

$21{ }^{4}$ Institute of Medical Genetics and Human Genetics, Charité-Universitätsmedizin Berlin,

22 Humboldt-Universität zu Berlin and Berlin Institute of Health, Berlin, Germany;

$23 \quad{ }^{5}$ A.I. DuPont Hospital for Children/Nemours, Wilmington, DE, USA;

$24{ }^{6}$ Berlin Center for Rare Diseases, Charité-Universitätsmedizin Berlin, Humboldt-

25 Universität zu Berlin and Berlin Institute of Health, Berlin, Germany;

$26{ }^{7}$ Berlin Institute of Health $($ BIIH) Berlin, Germany; 
medRxiv preprint doi: https://doi.org/10.1101/2020.12.28.20248193; this version posted July 22,2021 . The copyright holder for this preprint

$27 \quad{ }^{8}$ Institute for Medical Biometry, Informatics and Epidemiology, Medical

28 Faculty, University of Bonn, Bonn, Germany;

$29 \quad{ }^{9}$ Core Unit for Bioinformatics Data Analysis, Medical Faculty, University

30 of Bonn, Bonn, Germany;

$31{ }^{10}$ GeneTalk, Bonn, Germany;

$32{ }^{11}$ Institut für Medizinische Biochemie und Molekularbiologie (IMBM),

33 Universitätsmedizin Greifswald, Greifswald, Germany;

$34 \quad{ }^{12} \mathrm{CHU}$ Nantes, Service de Génétique Médicale, Nantes, France;

$35{ }^{13}$ |'Institut du Thorax, INSERM, CNRS, Université de Nantes, Nantes, France;

$36{ }^{14}$ Institute of Human Genetics, University of Bonn, Medical Faculty \& University

37 Hospital Bonn, Bonn, Germany;

$38{ }^{15}$ Center for Rare Diseases Bonn, University Hospital Bonn, Bonn, Germany;

$39{ }^{16}$ Institute of Medical Genetics and Applied Genomics, University of Tübingen,

40 Tübingen, Germany;

$41{ }^{17}$ Institute of Human Genetics, School of Medicine, Technical University Munich,

42 Munich, Germany;

$43{ }^{18}$ Institute of Neurogenomics, Helmholtz Zentrum München $\mathrm{GmbH}$, German Research

44 Center for Environmental Health, Neuherberg, Germany;

$45{ }^{19}$ Norwegian Research Center for Computers and Law, Faculty of Law, University of

46 Oslo, Oslo, Norway;

$47{ }^{20}$ Institute of Human Genetics and Department of Pediatrics, Medical Faculty, Heinrich

48 Heine University, Düsseldorf, Germany;

$49{ }^{21}$ Department of Human Genetics and George A. Jervis Clinic, NYS Institute for Basic

50 Research in Developmental Disabilities, Staten Island NY 10314, USA;

$51 \quad{ }^{22}$ Biology PhD Program, The Graduate Center, The City University of New York, New

52 York, United States of America;

$53 \quad{ }^{23}$ Institute of Human Genetics, University of Lübeck, Lübeck, Germany; 
medRxiv preprint doi: https://doi.org/10.1101/2020.12.28.20248193; this version posted July 22,2021 . The copyright holder for this preprint (which was not certified by peer review) is the author/funder, who has granted medRxiv a license to display the preprint in perpetuity.

It is made available under a CC-BY-NC-ND 4.0 International license.

$54{ }^{24}$ Department of Human Genetics, University Hospital of Heidelberg, Heidelberg,

55 Germany;

$56+$ equally contributing first authors

57 * Corresponding author, pkrawitz@uni-bonn.de

58 
medRxiv preprint doi: https://doi.org/10.1101/2020.12.28.20248193; this version posted July 22, 2021. The copyright holder for this preprint

(which was not certified by peer review) is the author/funder, who has granted medRxiv a license to display the preprint in perpetuity.

It is made available under a CC-BY-NC-ND 4.0 International license .

\section{Abstract}

60 A large fraction of monogenic disorders causes craniofacial abnormalities with 61 characteristic facial morphology. These disorders can be diagnosed more efficiently 62 with the support of computer-aided next-generation phenotyping tools, such as 63 DeepGestalt. These tools have learned to associate facial phenotypes with the underlying syndrome through training on thousands of patient photographs. However, this "supervised" approach means that diagnoses are only possible if the disorder was part of the training set. To improve recognition of ultra-rare disorders, we created

67 GestaltMatcher, which uses a deep convolutional neural network based on the 68 DeepGestalt framework. We used photographs of 17,560 patients with 1,115 rare 69 disorders to define a "Clinical Face Phenotype Space". Distance between cases in the 70 phenotype space defines syndromic similarity, allowing test patients to be matched to 71 a molecular diagnosis even when the disorder was not included in the training set.

72 Similarities among patients with previously unknown disease genes can also be 73 detected. Therefore, in concert with mutation data, GestaltMatcher could accelerate 74 the clinical diagnosis of patients with ultra-rare disorders and facial dysmorphism, as 75 well as enable the delineation of novel phenotypes. 
medRxiv preprint doi: https://doi.org/10.1101/2020.12.28.20248193; this version posted July 22, 2021. The copyright holder for this preprint

\section{Introduction}

77 Rare genetic disorders affect more than $6.2 \%$ of the global population ${ }^{1}$. Because 78 genetic disorders are rare and diverse, accurate clinical diagnosis is a time-consuming 79 and challenging process, often referred to as the "diagnostic odyssey," and all 80 informative clinical features have to be taken into consideration. A large fraction of 81 patients, particularly those with neurodevelopmental disorders, exhibits craniofacial abnormalities ${ }^{3}$. If the facial phenotype ("gestalt") is highly recognizable, such as in Down syndrome, it may also play an important role in establishing the diagnosis. Sometimes the gestalt is so characteristic or distinct that it reduces the search space of candidate genes or can be used to delineate novel phenotype-gene associations ${ }^{4}$. However, the ability to recognize these syndromic disorders relies heavily on the clinician's experience. Reaching a diagnosis is very challenging if the clinician has not previously seen a patient with an ultra-rare disorder or if the patient presents with a novel disorder, both of which are increasingly common scenarios.

With the rapid development of machine learning and computer vision, a considerable number of next-generation phenotyping tools have emerged that can analyze facial dysmorphology using two-dimensional (2D) portraits of patients ${ }^{5-13}$. These tools can aid in the diagnosis of patients with facial dysmorphism by matching their facial phenotype with that of known disorders. In 2014, Ferry et al. proposed using a Clinical Face Phenotype Space (CFPS) formed by facial features extracted from images to perform syndrome classification; the system in that study was trained on photos of more than 1,500 controls and 1,300 patients with eight different syndromes ${ }^{5}$. Since then, facial recognition technologies have improved significantly and constitute the core of the deep-learning revolution in computer vision ${ }^{14,15}$. The current state-of-the-art

100 framework for syndrome classification, DeepGestalt (Face2Gene, FDNA inc, USA), 101 has been trained on more than 20,000 patients and currently achieves high accuracy 
medRxiv preprint doi: https://doi.org/10.1101/2020.12.28.20248193; this version posted July 22, 2021. The copyright holder for this preprint

(which was not certified by peer review) is the author/funder, who has granted medRxiv a license to display the preprint in perpetuity.

It is made available under a CC-BY-NC-ND 4.0 International license.

102 in identifying the correct syndrome for roughly 300 syndromes $^{12,16}$. DeepGestalt has

103 also demonstrated a strong ability to separate specific syndromes and subtypes,

104 surpassing human experts' performance ${ }^{12}$. Hence, pediatricians and geneticists

105 increasingly use such next-generation phenotyping tools for differential diagnostics in

106 patients with facial dysmorphism. However, most existing tools, including DeepGestalt,

107 need to be trained on large numbers of photographs, and are therefore limited to

108 syndromes with at least seven images of different patients. The number of submissions

109 to diagnostic databases of pathogenic variants, such as ClinVar ${ }^{17}$, has become a good

110 surrogate for the prevalence of rare disorders. When submissions to ClinVar of disease

111 genes with pathogenic mutations are plotted in decreasing order, most of the

112 supported syndromes are on the left, indicating relatively high prevalence (Figure 1).

113 For instance, Cornelia de Lange syndrome (CdLS), which has been modeled by

114 multiple tools ${ }^{5,12}$, is caused by mutations in NIPBL, SMC1A, or HDAC8, as well as other

115 genes, and has been linked to hundreds of reported mutations. However, more than

116 half of the genes in ClinVar have fewer than ten submissions each (Figure 1). As a

117 result, most phenotypes have not been modeled because sufficient data are lacking.

118 Thus, the need to train on large numbers of photographs is a major limitation for the

119 identification of ultra-rare syndromes.

120 A second limitation of classifiers such as DeepGestalt is that their end-to-end, offline-

121 trained architecture does not support new syndromes without additional modifications.

122 In order to model a new syndrome in a deep convolutional neural network (DCNN), the

123 developer has to go through six separate steps (Supplementary Figure 1), including

124 collecting images of the new syndrome; changing the classification head, which is the

125 last layer of the DCNN; retraining the network; and more. In addition, the model cannot

126 be used to quantify similarities among undiagnosed patients, which is crucial in the

127 delineation of novel syndromes. 
medRxiv preprint doi: https://doi.org/10.1101/2020.12.28.20248193; this version posted July 22, 2021. The copyright holder for this preprint

(which was not certified by peer review) is the author/funder, who has granted medRxiv a license to display the preprint in perpetuity.

It is made available under a CC-BY-NC-ND 4.0 International license.

128 A third shortcoming of current approaches is that they are not able to contribute to the

129 longstanding discussion within the nosology of genetic diseases about

130 distinguishability. Syndromic differences have been hard to measure objectively ${ }^{18}$, and

131 decisions to "split" syndromes into separate entities on the basis of perceived

132 differences or to "lump" syndromes together on the basis of similarities have been

133 made subjectively. Current tools are unable to quantify the similarities between

134 syndromes in a way that could shed light on the underlying molecular mechanisms and

135 guide classification.

136 Our objective is to improve phenotypic decision support for rare disorders. Here we

137 describe GestaltMatcher, an innovative approach that uses an image encoder to 138 convert all features of a facial image into a vector of numbers. The encoder can also 139 be thought of as the penultimate layer of a DCNN that was trained on known 140 syndromes, such as DeepGestalt. The vectors resulting from the encoder are then 141 used to build a CFPS for matching a patient's photo to a gallery of portraits of solved 142 or unsolved cases. The distance between cases in the CFPS quantifies the similarities 143 between the faces, thereby matching patients with known syndromes or identifying 144 similarities between multiple patients with unknown disorders and thereby helping to 145 define new syndromes. Because GestaltMatcher quantifies similarities between faces 146 in this way, it addresses all three of the limitations described above: (1) it can identify 147 "closest matches" among patients with known or unknown disorders, regardless of 148 prevalence; (2) it does not need new architecture or training to incorporate new 149 syndromes; and (3) it creates a search space to explore similarity of facial gestalts 150 based on mutation data, which can point to shared molecular pathways of 151 phenotypically similar disorders. 
medRxiv preprint doi: https://doi.org/10.1101/2020.12.28.20248193; this version posted July 22, 2021. The copyright holder for this preprint (which was not certified by peer review) is the author/funder, who has granted medRxiv a license to display the preprint in perpetuity.

It is made available under a CC-BY-NC-ND 4.0 International license .

153 The feature encoder of GestaltMatcher computes a Facial Phenotypic Descriptor (FPD)

154 for each portrait image (Figure 2a). Each FPD can be thought of as one coordinate in 155 the CFPS (Figure 2b). The distances between the FPDs in the CFPS form the basis 156 for syndrome classification, delineation of novel phenotypes, and patient clustering. 157 The performance for all three of these use cases depends on the composition of the 158 training set and the gallery. All benchmarking results described in this section, as well 159 as those available through the web service, are based on data from Face2Gene (F2G).

160 The F2G dataset was used to construct a CFPS consisting of 26,065 images from 16117,502 subjects who had been diagnosed with a total of 1,115 different syndromes, 162 each supported by at least two cases. We divided the dataset into two categories, the 163 rare dataset consisting of 816 ultra-rare and novel syndromes, representing 164 syndromes that we aim to identify, and the frequent set, consisting of 299 syndromes 165 already identified by DeepGestalt. The latter set of known syndromes was also used 166 to train the encoder. Each category was further split into a gallery $(90 \%$ of each 167 syndrome) and a test set (the remaining $10 \%$ of each syndrome) (see the Online 168 methods for details).

169 Since F2G data cannot be shared, we compiled the GestaltMatcher database (GMDB), 170 consisting of 4,306 images from 3,693 subjects with 257 different syndromes. This 171 second data set is based on 902 publications, and further cases for which we obtained 172 consent for sharing. All findings described in this section that are based on the F2G 173 data can be reproduced qualitatively on the GMDB data and are listed in the 174 Supplemental Material.

175 Training on images of dysmorphism improves the performance of the FPD

176 To investigate the importance of using a syndromic features encoder rather than a 177 normal facial features encoder, we compared FPDs that are based on the same 178 architecture, but trained on different data. The first encoder, which we refer to as Enc- 
medRxiv preprint doi: https://doi.org/10.1101/2020.12.28.20248193; this version posted July 22, 2021. The copyright holder for this preprint

(which was not certified by peer review) is the author/funder, who has granted medRxiv a license to display the preprint in perpetuity.

It is made available under a CC-BY-NC-ND 4.0 International license.

179 healthy, was only trained on data from healthy individuals in CASIA-WebFace ${ }^{19}$. The

180 second encoder, which we refer to as Enc-F2G (for Face2Gene), was first trained on

181 the faces of healthy subjects and then fine-tuned by training on dysmorphic faces from

182 the gallery of patients with frequent syndromes. All images were encoded separately

183 for each encoder. We then evaluated the performance of the encoders on test sets of

184 syndromes from the frequent set and from the rare set. The performance metric was

185 the percentage of test cases (with known diagnosis) for which an FPD with the

186 matching disorder was within the $k$ closest diagnoses in the CFPS (the top-kaccuracy).

187 The features created by Enc-F2G performed better in the matching process than those

188 created with Enc-healthy (Table 1). This emphasizes the importance of training the

189 encoder on data from faces with dysmorphic phenotypes and not only on healthy faces.

190 The features created by Enc-F2G improved the accuracy of matching within the top-

19110 closest images from $31.46 \%$ to $49.12 \%$ for the frequent category. Furthermore, the

192 top-10 accuracy improved from $21.77 \%$ to $29.56 \%$ for the rare syndromes, which do

193 not overlap with the frequent syndromes. The larger relative improvement of $56 \%$ on

194 the frequent test set versus $36 \%$ for the rare set could possibly be explained as Enc-

195 F2G being better suited to encode syndromes of the frequent set because it was

196 previously trained on these disorders. Likewise, for some of the 816 novel disorders,

197 the characteristic features were not yet optimally represented by Enc-F2G because

198 features of these disorders were not part of the training set.

199 The same trend of improvement by fine-tuning on a diverse but smaller set of 200 syndromic photos is also seen on the public GMDB dataset (Enc-GMDB vs Enc-F2G 201 in Supplementary Table 1). These results suggest that an encoder that is fine-tuned 202 on as many syndromic faces as possible, such as DeepGestalt, is a better fit for the 203 task of syndrome classification than one trained only on healthy faces. Moreover, 204 DeepGestalt's FPD provides a better generalization or clustering than the FPD 205 encoded by CASIA for rare syndromes that it had not previously seen. 
medRxiv preprint doi: https://doi.org/10.1101/2020.12.28.20248193; this version posted July 22, 2021. The copyright holder for this preprint (which was not certified by peer review) is the author/funder, who has granted medRxiv a license to display the preprint in perpetuity.

It is made available under a CC-BY-NC-ND 4.0 International license .

\section{Syndromic diversity improves the performance on novel disorders}

207 Earlier definitions of the FPD were mainly based on training a network with a small selection of common and highly characteristic syndromes ${ }^{5,9}$. In principle, we could train GestaltMatcher's encoder on all 1,115 different syndromes in our dataset. However, most of the facial phenotypes that have recently been linked to a gene are either ultrarare or less distinctive, and using a very unbalanced training set with many ultra-rare

212 disorders linked to only few cases may add noise without substantial additional benefit.

213 We therefore analyzed the influence of the number of syndromes on the encoder's 214 fine-tuning by incrementally increasing their number starting with the most frequent ones. Due to the imbalance among the disorders added each time, the improvement could be affected by the additional number of training subjects. Therefore, we used the

217 same number of subjects for each syndrome. In this section, the test set consists only 218 of disorders from the rare set that the encoder has not seen. The training procedure 219 and averaging of the readout is described in detail in the Online methods.

220 When we increase the number of training syndromes, the accuracy increases (Figure 221 3). In general, the performance is also higher when more individuals per syndrome are used for training. Particularly when more than 50 syndromes are used, the curve for

223 training with 20 subjects/syndrome is above the curve for 10 subjects/syndrome, and 224 so on. The same trend is also shown in the public GMDB dataset (Supplementary 225 Figures 2 and 3).

226 Moreover, double the number of syndromes is better than double the number of 227 subjects in most of the combinations (Supplementary Figure 4). The effect of doubling 228 the number of syndromes used for training is greater when the base sample size is 229 larger than 1200 subjects (Supplementary Figures 5 and 6). Therefore, both of the 230 findings suggest that increasing the syndromic diversity in the training set improves the 231 performance on novel disorders. 
medRxiv preprint doi: https://doi.org/10.1101/2020.12.28.20248193; this version posted July 22,2021 . The copyright holder for this preprint

(which was not certified by peer review) is the author/funder, who has granted medRxiv a license to display the preprint in perpetuity.

It is made available under a CC-BY-NC-ND 4.0 International license .

232 Top-10 accuracy plateaus when encoders are fine-tuned on more than 150

233 syndromes

234 In the previous section, we analyzed the impact of syndromic diversity in a balanced 235 setting, that is, the dynamics of increasing the number of syndromes while keeping the 236 size of the increments (the number of added subjects) equal. In this section we analyze

237 the influence of the number of syndromes on model training in the real-world scenario; 238 that is, when using all of the subjects per syndrome (Supplementary Figure 7). The 239 top-10 accuracy improved considerably until about 150 syndromes, representing 240 roughly $90 \%$ of the subjects in the entire training set. Almost doubling the number of 241 syndromes to 299 with the remaining $10 \%$ of subjects only increases the performance 242 marginally. From these dynamics, we can conclude that including additional 243 syndromes beyond 299 for defining the FPD will provide little benefit, and we decided 244 to proceed with the Enc-F2G encoder in the following section that is based on the 299 245 syndromes described in the original DeepGestalt paper.

Performance comparison between GestaltMatcher and DeepGestalt

247 To validate the GestaltMatcher approach, we first worked with the 323 images of 248 patients with 91 syndromes from the London Medical Database (LMD) ${ }^{20}$ that were 249 already used for benchmarking the performance of DeepGestalt ${ }^{12}$. When using the 250 frequent gallery, which contains syndromes that DeepGestalt currently supports, 251 GestaltMatcher achieved $64.30 \%$ and $86.59 \%$ accuracy within the top-10 and top-30 252 ranks, respectively, which was lower than the $81.28 \%$ top-10 accuracy and $88.34 \%$ 253 top-30 accuracy achieved by DeepGestalt with a Enc-F2G softmax approach 254 (Supplementary Table 2 and 3). However, when we used the gallery of all 1,115 255 syndromes for GestaltMatcher (frequent + rare) which is a search space that is roughly 256 four times larger, the top-10 and top-30 dropped by only 2.40 percentage points and 2575.17 percentage points, respectively (Supplementary Table 2). Moreover, we 
medRxiv preprint doi: https://doi.org/10.1101/2020.12.28.20248193; this version posted July 22, 2021. The copyright holder for this preprint (which was not certified by peer review) is the author/funder, who has granted medRxiv a license to display the preprint in perpetuity.

It is made available under a CC-BY-NC-ND 4.0 International license .

performed the same evaluation on the F2G-frequent test set and GMDB-frequent test set. When the number of syndromes in the gallery was increased from 299 to 1,115 , the top-10 and top-30 also dropped slightly by 2.27 and 3.77 percentage points for the F2G-frequent test set (Table 1). The results of the GMDB frequent test also dropped slightly while supporting more than twice the number of syndromes (Supplementary Table 1). These results indicate that the GestaltMatcher clustering approach is highly scalable and robust to adding new disorders, without the limitations of a classification approach.

\section{Matching undiagnosed patients from unrelated families}

In the second use case, we envision GestaltMatcher as a phenotypic complement to GeneMatcher ${ }^{21}$. To prove that we can match patients from unrelated families who have the same disease by using only their facial photos, we selected syndromes from 15 recent GeneMatcher publications with titles containing the phrase "facial dysmorphism". In contrast to the benchmarking of the previous section, the gallery now consists of subjects with rare syndromes to simulate undiagnosed subjects and as a consequence, ranks refer to individuals and not disorders. For the evaluation we still have to reveal in the end whether an individual from the gallery is a match for a test case or not. This implies that non-matching cases can harm the performance more than in the previous section. For instance, if the first matching individual is at rank 30 , but the 29 non-matching individuals with higher similarity to the test case all together have only four non-matching disorders, then this match would contribute to the top-5 accuracy in the previous section that matched on disorders but to the top-30 accuracy in this section that matches to individuals. Only the top-1 accuracy remains the same in both benchmarks.

In this scenario, we matched 30 of 91 subjects and connected 26 of 79 families when using the top-10 criterion (Table 2 and Supplementary Figure 8). When using the top- 
medRxiv preprint doi: https://doi.org/10.1101/2020.12.28.20248193; this version posted July 22, 2021. The copyright holder for this preprint (which was not certified by peer review) is the author/funder, who has granted medRxiv a license to display the preprint in perpetuity.

It is made available under a CC-BY-NC-ND 4.0 International license .

28430 rank, 48 of 91 subjects were matched, and 40 of 79 families were connected. Enc-

285 healthy, which is trained only with healthy subjects, matched only 40 out of 91 subjects

286 and connected 34 out of 79 families using the top-30 rank (Supplementary Table 4).

287 Hence, using the encoder trained with facial dysmorphic subjects improves the

288 matching considerably.

289 As an example, in a study of TMEM9422, eight of the ten photos in six different families

290 were matched, and five of six families were connected within the top-10 rank. When

291 the three test images in family 2 (F-2-5, F-2-7, F-2-9) were tested, the other five families

292 were among those in the top-30 rank (Figure 4). The youngest brother, F-2-5, matched

293 families 1, 3, 5, and 6, and one sister, F-2-7, matched families 1, 4, and 6. Another

294 sister, F-2-9, matched families 1, 4, 5, and 6. The six families were recruited at five

295 different institutes in India, Qatar, the United States (NIH Undiagnosed Diseases

296 Network), and Switzerland, indicating that GestaltMatcher can also connect patients of

297 different ethnic origins. However, a more systematic analysis of pairwise distances still

298 revealed considerably smaller distances between subjects with de novo mutations and

299 their family members than between these subjects and unrelated individuals

300 (Supplementary Figure 9). This reflects similarities in the nonclinical features of the

301 face, which is also higher within the same ethnicity and is a known confounding factor

302 for the GestaltMatcher approach. However, it is a bias that can be attenuated ${ }^{23}$ and

303 will also diminish over time when more diverse training data become available ${ }^{24}$.

304 GestaltMatcher and human experts agree on syndrome distinctiveness

305 We hypothesized that some of the ultra-rare disorders that were linked to their disease306 causing genes early on, such as Schuurs-Hoeijmakers syndrome in $2012,{ }^{25}$ have 307 particularly distinctive facial phenotypes. To systematically analyze the dependence of 308 disease-gene discovery on the distinctiveness of a facial gestalt, we asked three expert 309 dysmorphologists (S.M., N.E., and K.W.G.) to grade 299 syndromes on a scale from 1 
medRxiv preprint doi: https://doi.org/10.1101/2020.12.28.20248193; this version posted July 22, 2021. The copyright holder for this preprint

(which was not certified by peer review) is the author/funder, who has granted medRxiv a license to display the preprint in perpetuity.

It is made available under a CC-BY-NC-ND 4.0 International license .

310 to 3 . The more easily they could distinguish the diseases, and the more characteristic

311 of the disease they deemed the facial features, the higher the score. All three

312 syndromlogists agreed on the same score for 195/299 syndromes, yielding a

313 concordance of $65.2 \%$. We then selected 50 syndromes as a test set and trained the

314 model with the remaining 249 syndromes. We analyzed the correlation of the mean of

315 the distinctiveness score from human experts with the top-10 accuracy that

316 GestaltMatcher achieves for these syndromes without having been trained on them

317 (Figure 5a, Supplementary Table 6). The Spearman's rank correlation coefficient was

$3180.400(P=0.004)$, indicating a clear positive correlation between distinctiveness score

319 and top-10 accuracy. Syndromes with a higher average score tended to perform better,

320 with Schuurs-Hoeijmakers syndrome being amongst the best-performing syndromes

321 in GestaltMatcher. The analysis on 20 selected syndromes from the GMDB dataset

322 also showed a positive correlation between distinctiveness score and top-5 accuracy

323 (Supplementary Figure 10 and Supplementary Table 7).

324 The correlation for GestaltMatcher accuracy and disease prevalence was not 325 significant $(P=0.130$; Figure $5 b)$. This also means that ultra-rare disorders share a 326 similar distribution of distinctiveness with more common ones, which is important for 327 estimates about the performance of GestaltMatcher on novel phenotypes in the real 328 world.

\section{Characterization of phenotypes in the CFPS}

330 When syndromologists cannot find a molecular cause for a patient's phenotype in 331 diagnostic-grade genes after extensive work up in the lab, it becomes a research case 332 and they may compare the patient's condition to known disorders. For example a 333 potentially novel phenotype could be described as "syndrome $X Y$-like" to build a case 334 group for further molecular analysis through genome sequencing. In GestaltMatcher, 
medRxiv preprint doi: https://doi.org/10.1101/2020.12.28.20248193; this version posted July 22, 2021. The copyright holder for this preprint

(which was not certified by peer review) is the author/funder, who has granted medRxiv a license to display the preprint in perpetuity.

It is made available under a CC-BY-NC-ND 4.0 International license.

335 this is the third use case, and such comparisons can be supported by cluster analysis

336 in the CFPS with the cosine distance as a similarity metric (Supplementary Table 8).

337 If a novel disease gene has been identified and the similarities of the patients to known

338 phenotypes outweigh the differences, OMIM groups them into a phenotypic series. On

339 the gene or protein level, such phenotypic series often correspond to molecular-

340 pathway diseases, such as GPI-anchor deficiencies for hyperphosphatasia with mental

341 retardation syndrome (HPMRS) or cohesinopathies for CdLS. For our cluster analysis,

342 we sampled subjects in our database with subtypes of four large phenotypic series and

343 found high intersyndrome separability in addition to considerable intrasyndrome

344 substructure in Noonan syndrome, CdLS, Kabuki syndrome, and

345 mucopolysaccharidosis. A $t-S_{N E}^{26}$ projection of the FPDs into two dimensions yielded

346 the best visualization results (Supplementary Figure 11). Although any projection into

347 a smaller dimensionality might cause a loss of information, the clusters are still clearly

348 visible for the 743 subjects sampled from these four phenotypic series. This

349 observation provides further evidence that characteristic phenotypic features are

350 encoded in the FPDs.

351 To demonstrate the separability of syndromes with facial dysmorphism, we also used

$352 t$-SNE to project 4,353 images of the ten syndromes from the frequent set with the

353 largest number of subjects and 872 images of ten non-distinct syndromes (syndromes

354 without facial dysmorphism) into 2D space. In addition, we calculated the Silhouette

355 index ${ }^{27}$ for both of these datasets. The FPDs of the frequent syndromes showed ten

356 clear clusters of subjects (Supplementary Figure 12), but the $t$-SNE projection of

357 subjects with non-distinct syndromes created no clear clusters. Moreover, the

358 Silhouette index of the frequent syndromes (0.11) was higher than that of the non-

359 distinct syndromes (-0.005); the negative Silhouette index indicates poor separation

360 of the non-distinct syndromes. 
medRxiv preprint doi: https://doi.org/10.1101/2020.12.28.20248193; this version posted July 22, 2021. The copyright holder for this preprint (which was not certified by peer review) is the author/funder, who has granted medRxiv a license to display the preprint in perpetuity.

It is made available under a CC-BY-NC-ND 4.0 International license .

361

362

\section{GestaltMatcher as a tool for clinician scientists}

The transition of a research case to a diagnostic case is best described by the process of matching unrelated patients in the CFPS who share a molecular abnormality until statistical significance is reached. We illustrate this process for the novel disease gene PSMC3 in a demonstration on the GestaltMatcher web service (Supplementary Figure 13, www.gestaltmatcher.org). Ebstein et al. (not yet published) report 18 patients with a neurodevelopmental disorder of heterogeneous dysmorphism that is caused by de novo missense mutations in PSMC3, which encodes a proteasome $26 \mathrm{~S}$ subunit. Although not all PSMC3 patients have the same facial phenotype, the proximity of two unrelated patients in the CFPS who share the same de novo PSMC3 mutation is exceptional. Their distance is comparable to the pairwise distances of patients with the recurring missense mutation $\mathrm{R} 203 \mathrm{~W}$ in PACS1, which is the only known cause of Schuurs-Hoeijmakers syndrome. On the one hand, the high distinctiveness of these two PSMC3 cases with the same mutation allows direct matching by phenotype. On the other hand, the pairwise similarities of 10 out of 18 patients in the CFPS for which portraits were available also hints that the protein domains have more than one function. The previously described scalability of GestaltMatcher makes an exploration of such similarities in the CFPS possible for any number of cases as soon as they have been added to the gallery of undiagnosed patients.

\section{Discussion}

GestaltMatcher's ability to match previously unseen syndromes, that is, those for which no patient is included in the training set, distinguishes it from other approaches. Since matching of unseen syndromes is not only of importance for ultra-rare disorders but can be considered for the discovery of novel diseases, GestaltMatcher could also speed up the process of delineating new disorders. 
medRxiv preprint doi: https://doi.org/10.1101/2020.12.28.20248193; this version posted July 22, 2021. The copyright holder for this preprint (which was not certified by peer review) is the author/funder, who has granted medRxiv a license to display the preprint in perpetuity.

It is made available under a CC-BY-NC-ND 4.0 International license.

386 Importantly, GestaltMatcher provides the flexibility to easily scale up the number of

387 supported syndromes or the number of unsolved cases without substantial loss in 388 performance. The LMD validation analysis revealed that the use of the softmax 389 approach, that is classification based on the values of the last layer representing 390 disorders, outperformed GestaltMatcher. However, the GestaltMatcher encoder, that 391 is clustering in the CFPS with values of the penultimate layer representing features, demonstrated high scalability by yielding similar performance when the number of 393 supported syndromes was increased from 299 to 1,115. Furthermore, the 394 distinctiveness of a syndrome correlated with the performance (Figure 5a), whereas 395 syndrome prevalence did not (Figure 5b). Thus, GestaltMatcher can match a syndrome 396 with a distinguishable facial gestalt even if it is of extremely low prevalence. This enables us to avoid the long development flow currently required to support and discover novel syndromes (Supplementary Figure 1). Instead, matching can be offered 399 instantly for all unsolved cases with available frontal images for which consent has 400 been provided for inclusion in the tool. If the gallery is populated by cases with a 401 disease-causing mutation in a diagnostic-grade gene, we consider this a diagnostic work-up. In contrast, if the gallery is populated by further undiagnosed cases, it is a use case comparable to GeneMatcher.

404 GestaltMatcher's framework also allows us to abstract the encoding of a dataset away 405 from the classification task. For example, one can evaluate both phenotypic series and 406 pleiotropic genes within a single CFPS, or obtain the most-similar patients for each of 407 the matched syndromes, with minor computational cost (i.e., in real time). Furthermore, 408 the GestaltMatcher framework computes the similarity between each of the test set 409 images across the entire dataset of images. This similarity can be computed using 410 different metrics, e.g., cosine or Euclidean distance. The results are then aggregated 411 according to the chosen configuration. For example, image similarity can be 412 aggregated at the patient level or the syndrome level. Furthermore, the dataset can be 
medRxiv preprint doi: https://doi.org/10.1101/2020.12.28.20248193; this version posted July 22,2021 . The copyright holder for this preprint

(which was not certified by peer review) is the author/funder, who has granted medRxiv a license to display the preprint in perpetuity.

It is made available under a CC-BY-NC-ND 4.0 International license .

413 filtered according to different parameters (such as ethnicity, disease-causing genes, or

414 age) to further customize the evaluation.

415 One of the key features of GestaltMatcher is the ability to match patients and quantify

416 their syndromic similarity. For clinician scientists who often face two different tasks in

417 their daily practice, this means: (1) assessing whether the patient's phenotype is

418 specific for a known disorder. If e.g. a variant of unclear clinical significance is found in

419 a diagnostic grade gene, this would be considered as supporting evidence for the

420 pathogenicity ${ }^{28,29}$. (2) assessing whether the phenotypic similarity of an unsolved case

421 to other individuals without a diagnosis is high enough to form e.g. a case group that

422 is further analyzed. This could e.g. result in the identification of potentially deleterious

423 variants in a novel disease gene and would represent the phenotypic complement to

424 existing matching approaches on the molecular level. Several online platforms, such

425 as GeneMatcher, MyGene2 (https://mygene2.org/MyGene2), and Matchmaker

426 Exchange ${ }^{30}$, already allow physicians to look for similar patients based on sequencing

427 information, and over the past few years these platforms have enabled the matching

428 of thousands of patients. However, although phenotypic data, encoded e.g. in HPO

429 terms, are usually exchanged after contact has been established, automated facial

430 matching technology has not yet been included in any of these platforms.

431 Since its first proof of concept, in which GestaltMatcher was used to identify two 432 unrelated patients from different countries with the same novel disease, caused by the 433 same de novo mutation in $L E M D 2^{4}$, our approach has successfully been applied to 434 further ultra-rare disorders (Figure 1). We matched 40 of 79 different families in 15 435 GeneMatcher publications by top-30 rank (Table 2 and Supplementary Figure 8), and 43611 candidate genes are currently under evaluation. This result shows the power and 437 potential of GestaltMatcher to identify novel syndromes. Although the number of 438 individuals and the diversity of their phenotypes will affect the performance, cases with 
medRxiv preprint doi: https://doi.org/10.1101/2020.12.28.20248193; this version posted July 22, 2021. The copyright holder for this preprint

(which was not certified by peer review) is the author/funder, who has granted medRxiv a license to display the preprint in perpetuity.

It is made available under a CC-BY-NC-ND 4.0 International license .

439 a high syndromic similarity will remain matchable due to the high dimensionality of the

440 CFPS.

441 We therefore hope that GestaltMatcher will be readily integrated into other matching

442 platforms to aid in determining which phenotypes should be grouped together into a

443 syndrome or phenotypic series, as well as linking individual patients to a molecular 444 diagnosis.

\section{Code availability}

446 GestaltMatcher is a partially proprietary framework. Although the source code for 447 cropping the face cannot be shared, the architecture of the CNN, as well as a web 448 service of the trained version of the tool is accessible for use by health care 449 professionals free of charge at www.gestaltmatcher.org.

\section{Data availability}

451 The data that support the findings of this study are divided into two groups, sharable

452 data (GMDB) and non-sharable data (F2G). GMDB is accessible via 453 www.gestaltmatcher.org. Restricted data are curated from Face2Gene users under a 454 license and cannot be published in order to protect patient privacy.

\section{Online methods}

\section{Study approval}

457 This study is governed by the following Institutional Review Board (IRB) approval:

458 Charité-Universitätsmedizin Berlin, Germany (EA2/190/16); UKB Universitätsklinikum

459 Bonn, Germany (Lfd.Nr.386/17). The authors have obtained written informed consent 460 given by the patients or their guardians, including permission to publish photographs.

\section{$461 \quad$ Face2Gene datasets}


medRxiv preprint doi: https://doi.org/10.1101/2020.12.28.20248193; this version posted July 22, 2021. The copyright holder for this preprint

(which was not certified by peer review) is the author/funder, who has granted medRxiv a license to display the preprint in perpetuity.

It is made available under a CC-BY-NC-ND 4.0 International license.

462 We collected images of subjects with clinically or molecularly confirmed diagnoses

463 from the Face2Gene database (https://www.face2gene.com). Extracted, deidentified

464 data were used to remove poor-quality or duplicated images from the dataset without

465 viewing the photos. After removing images of insufficient quality, the dataset consisted

466 of 26,152 images from 17,560 subjects with a total of 1,115 syndromes

467 (Supplementary Table 9).

468 GestaltMatcher was designed to distinguish syndromes with different properties. We 469 separated syndromes by the number of affected subjects and whether they had 470 already been learned by the DeepGestalt model. Supplementary Figure 14 provides 471 an overview of how the dataset was divided. The current DeepGestalt approach 472 requires at least seven subjects to learn a novel syndrome. We first used this threshold 473 to separate the syndromes into "frequent" and "rare" syndromes. The objective of our 474 study was to improve phenotypic decision support for "rare disorders". However, 475 frequent syndromes that are not associated with facial dysmorphic features cannot be 476 modeled by DeepGestalt. We therefore further selected 299 frequent syndromes that 477 possess characteristic facial dysmorphism recognized by DeepGestalt as "frequent 478 syndromes". The frequent syndromes were used to validate syndrome prediction and 479 the separability of subtypes of a phenotypic series because these syndromes are known to have facial dysmorphic features that are well recognized by the DeepGestalt

481 encoder. For rare syndromes, we sought to demonstrate that GestaltMatcher could 482 predict a syndrome even if facial images were publicly available for only a few subjects. 483 It is noteworthy that, for more than half of all known disease-causing genes, fewer than 484 ten cases with pathogenic variants have been submitted to ClinVar (Figure 1). Of the 1,115 syndromes in the entire dataset, 299 were frequent and 816 were rare. DeepGestalt cannot yet be applied to rare syndromes. is the set of subjects that we intend to match, given a subject from the test set. First, 
medRxiv preprint doi: https://doi.org/10.1101/2020.12.28.20248193; this version posted July 22, 2021. The copyright holder for this preprint (which was not certified by peer review) is the author/funder, who has granted medRxiv a license to display the preprint in perpetuity.

It is made available under a CC-BY-NC-ND 4.0 International license .

$48990 \%$ of subjects with each frequent syndrome were used to train the models, and the

490 remaining $10 \%$ of subjects were used to validate the DeepGestalt training; the $90 \%$

491 then became the frequent gallery and the $10 \%$ were assigned to the frequent test set.

492 For the rare dataset, we performed 10-fold cross-validation. In each syndrome, 90\% 493 and $10 \%$ of subjects were assigned to the gallery and test set, respectively. The test 494 sets were designed to have the same distribution of distinctiveness as the training sets.

495 Matching only within a dataset would not represent a real-world scenario. Therefore, 496 the galleries of the two datasets were later combined into a unified gallery that was 497 used to search for matched patients.

498 Please note that the threshold of seven subjects to divide the dataset into frequent and 499 rare is to compare GestaltMatcher to DeepGestalt, which both use the same training 500 data. We could adjust this threshold higher or even remove this threshold in the future.

\section{GMDB dataset}

502 We collected images of subjects with clinically or molecularly confirmed diagnoses 503 from publications and individuals that gave appropriate informed consent for the 504 purpose of this study. This dataset can be used as a public training and test set for 505 benchmarking and is available at GestaltMatcher Database

506 (https://gestaltmatcher.gene-talk.de).

507 At the time of the data freeze on 9 June 2021, the dataset consisted of 4,306 images 508 of 3,693 subjects with a total of 257 syndromes from 902 publications (Supplementary 509 Table 9). Six of the 3,693 subjects have not yet been published, but appropriate 510 consent has been obtained. For a fair comparison with the Face2Gene dataset, we 511 performed the data separation in the same way. The dataset was first split by the same 512 threshold (seven subjects) into frequent and rare datasets, giving 139 syndromes in the frequent dataset and 118 syndromes in the rare set. Both datasets were also later 
medRxiv preprint doi: https://doi.org/10.1101/2020.12.28.20248193; this version posted July 22, 2021. The copyright holder for this preprint (which was not certified by peer review) is the author/funder, who has granted medRxiv a license to display the preprint in perpetuity.

It is made available under a CC-BY-NC-ND 4.0 International license .

514 separated into gallery and test sets. The data split is shown in Supplementary Figure

515 15. Of the 3,693 subjects in GMDB, 963 are also in Face2Gene dataset. To use the 516 GMDB rare set as the test set for both the GMDB frequent set and the Face2Gene 517 frequent set, we made sure that there is no syndrome that is in both the GMDB rare 518 set and Face2Gene frequent set (Supplementary Figure 16).

\section{DeepGestalt encoder}

520 The preprocessing pipeline of DeepGestalt includes point detection, facial alignment

521 (frontalization), and facial region cropping. During inference, a facial region crop is 522 forward passed through a deep convolutional network (DCNN) and ultimately gives the 523 final prediction of the input face image. The DeepGestalt network consists of ten 524 convolutional layers (Conv) with batch normalization (BN) and a rectified linear 525 activation unit (ReLU) to embed the input features. After every Conv-BN-ReLU layer, 526 a max pooling layer is applied to decrease spatial size while increasing the semantic 527 representation. The classifier part of the network consists of a fully connected linear 528 layer with dropout (0.5). In this study, we considered the DeepGestalt architecture as 529 an encoder-classification composition, pipelined during inference. We chose the last 530 fully connected layer before the softmax classification as the facial feature 531 representation (facial phenotypic descriptor, FPD), resulting in a vector of size 320.

532 DeepGestalt was first trained on images of healthy individuals from CASIA-WebFace ${ }^{19}$, 533 and later fine-tuned on a dataset with patient images (Face2Gene or GMDB). The 534 encoder without fine-tuning on patient images was called Enc-healthy. The encoder 535 later trained on 299 frequent syndromes in the Face2Gene dataset was named Enc536 F2G. The encoder trained on 139 frequent syndromes in GMDB was named Enc537 GMDB. In the following sections, we have several encoders trained on different 538 subsets of the Face2Gene and GMDB datasets. The summary of all the encoders used 539 in this study is shown in Supplementary Table 5. To compare GestaltMatcher and 
medRxiv preprint doi: https://doi.org/10.1101/2020.12.28.20248193; this version posted July 22, 2021. The copyright holder for this preprint

(which was not certified by peer review) is the author/funder, who has granted medRxiv a license to display the preprint in perpetuity.

It is made available under a CC-BY-NC-ND 4.0 International license.

540 DeepGestalt, we used a model using softmax for predicting syndromes, which we

541 called "Enc-F2G (softmax)". This model is the same as Enc-F2G; the only difference

542 is that Enc-F2G (softmax) used softmax in the last layer for prediction, as in

543 DeepGestalt, and Enc-F2G used the cosine distance of FPDs for prediction.

544 Our first hypothesis was that images of patients with the same molecularly diagnosed

545 syndromes or within the same phenotypic series, and who also share similar facial

546 phenotypes, can be encoded into similar feature vectors under some set of metrics.

547 Moreover, we hypothesized that DeepGestalt's specific design choice of using a

548 predefined, offline-trained, linear classifier could be replaced by other classification

549 "heads", for example, $k$-Nearest Neighbors using cosine distance, which we used for

550 GestaltMatcher.

551 Descriptor projection: Clinical Face Phenotype Space

552 Each image was encoded by the DeepGestalt encoder, resulting in a 320-dimensional

553 FPD. These FPDs were further used to form a 320-dimensional space called the

554 Clinical Face Phenotype Space (CFPS), with each FPD a point located in the CFPS,

555 as shown in Figure 2. The similarity between two images is quantified by the cosine

556 distance between them in the CFPS. The smaller the distance, the greater the similarity

557 between the two images. Therefore, clusters of subjects in the CFPS can represent

558 patients with the same syndrome, similarities among different disorders, or the

559 substructure under a phenotypic series.

\section{Evaluation}

561 To evaluate GestaltMatcher, we took the images in the test set as input and positioned

562 them in the CFPS defined by the images of the gallery. We calculated the cosine

563 distance between each of the test set images (for which the diagnoses were known in 564 this proof-of-concept study) and all of the gallery images. Then, for each test image, if 
medRxiv preprint doi: https://doi.org/10.1101/2020.12.28.20248193; this version posted July 22, 2021. The copyright holder for this preprint (which was not certified by peer review) is the author/funder, who has granted medRxiv a license to display the preprint in perpetuity.

It is made available under a CC-BY-NC-ND 4.0 International license .

565 an image from another subject with the same disorder in the gallery was among the

566 top-k nearest neighbors, we called it a top-k match. We then benchmarked the

567 performance by averaging the top- $k$ accuracy (percent of test images with correct 568 matches within the top $k$ ) of each syndrome to avoid biasing predictions toward the 569 major class. We further compared the accuracy of each syndrome in the frequent and 570 rare syndrome subsets to investigate whether GestaltMatcher can extend DeepGestalt 571 to support more syndromes. To compare its performance on predicting syndromes with

572 DeepGestalt, we first performed image aggregation on the syndrome level before 573 calculating top-kaccuracy, which means that only the nearest image of each syndrome 574 will be taken into account.

\section{London Medical Dataset validation analysis}

576 We compiled 323 images of patients diagnosed with 91 frequent syndromes from the $577 \mathrm{LMD}^{19}$ and used this as the validation set for frequent syndromes. We first evaluated 578 the validation set using softmax, which is a DeepGestalt method. To compare the 579 performance with that of GestaltMatcher, we evaluated the performance of 580 GestaltMatcher on two different galleries: a gallery of frequent syndromes consisting 581 of 19,950 images of patients with 299 syndromes, and a unified gallery consisting of 58222,298 images of patients with 1,115 syndromes. We then reported the top-k accuracy 583 and compared the results of these three settings (DeepGestalt with softmax, 584 GestaltMatcher with frequent gallery, and GestaltMatcher with unified gallery).

585 Rare syndromes analysis

586 To understand the potential for matching rare syndromes, we trained an encoder, 587 denoted Enc-F2G-rare, on 467 out of 816 rare syndromes with more than two and 588 fewer than seven subjects. Ninety percent of the subjects were used to train Enc-F2G589 rare and were later assigned to the gallery. The remaining $10 \%$ of subjects were 
medRxiv preprint doi: https://doi.org/10.1101/2020.12.28.20248193; this version posted July 22, 2021. The copyright holder for this preprint (which was not certified by peer review) is the author/funder, who has granted medRxiv a license to display the preprint in perpetuity.

It is made available under a CC-BY-NC-ND 4.0 International license .

590 assigned to the test set. We then compared the performance of Enc-F2G-rare and

591 Enc-F2G using cosine distance and the softmax classifier.

\section{Matching undiagnosed patients from unrelated families}

593 We selected 15 articles published from 2015 to 2019 in which GeneMatcher was used

594 to establish an association of a gene with a novel phenotype with facial dysmorphism 595 from unrelated families. In total, these studies contained 108 photos of 91 subjects 596 from 79 families. The details are shown in Table 2. The 15 genes were not among the 597 Face2Gene frequent syndromes, so we can consider them each as a novel phenotype 598 to the model. We performed leave-one-out cross-validation on this dataset; that is, we 599 kept one photo as the test set, and we assigned the rest of the photos to a gallery of 6003,533 photos with 816 rare syndromes to simulate the distribution of patients with 601 unknown diagnosis. We then evaluated the performance by top-1 to top-30 rank. If a 602 photo of another subject with the same disease-causing gene from an unrelated family 603 was among the top-k rank, we called it a match.

604 Moreover, we used top-k rank to measure how many unrelated families were 605 connected. If one unrelated family was among the test photo's top- $k$ rank, the families 606 were considered to be connected at that rank. How many families were matched to at 607 least one unrelated family was also represented.

608 When using the GeneMatcher data, we did not perform syndrome aggregation 609 because aggregation cannot be performed if the syndrome is not known. Instead, we 610 matched patients rather than predicting disorders.

\section{Syndrome facial distinctiveness score}

612 To evaluate the importance of the facial gestalt for clinical diagnosis of the patient, we 613 asked three dysmorphologists (co-authors Shahida Moosa, Nadja Ehmke, and Karen 
medRxiv preprint doi: https://doi.org/10.1101/2020.12.28.20248193; this version posted July 22,2021 . The copyright holder for this preprint

(which was not certified by peer review) is the author/funder, who has granted medRxiv a license to display the preprint in perpetuity.

It is made available under a CC-BY-NC-ND 4.0 International license .

614 W. Gripp) to score the usefulness of each syndrome's facial gestalt for establishing a

615 diagnosis. Three levels were established:

1. Facial gestalt can be supportive in establishing the clinical diagnosis.

2. Facial gestalt is important in establishing the clinical diagnosis, but diagnosis cannot be made without additional clinical features.

3. Facial gestalt is a cardinal symptom, and a visual or clinical diagnosis is possible based only on the facial phenotype.

621 We then averaged the grades from the three dysmorphologists for each syndrome.

\section{Syndrome prevalence}

623 The prevalence of each syndrome was collected from Orphanet (www.orpha.net). Birth

624 prevalence was used when the actual prevalence was missing. If only the number of 625 cases or families was available, we calculated the prevalence by summing the 626 numbers of all cases or families and dividing by the global population, using 7.8 billion 627 for the global population and a family size of ten for each family ${ }^{31}$.

\section{Unseen syndromes correlation analysis}

629 To investigate the influence of prevalence and distinctiveness score on the

630 performance of novel syndromes with facial dysmorphism, we selected 50 frequent 631 syndromes and kept them out of the training set. The 50 syndromes were selected to 632 have evenly distributed distinctiveness scores and prevalence distribution; the 633 distributions are shown in Supplementary Figure 17 and Supplementary Table 6. The 634 encoder (Enc-F2G-exclude-50) was trained on $90 \%$ of the subjects from the other 249 635 frequent syndromes. In addition, we performed random downsampling to remove the 636 confounding effect of prevalence. For each iteration, we randomly downsampled each 637 syndrome by assigning five subjects to the gallery and one subject to the test set. We 638 then averaged the top-10 accuracy of 100 iterations. We calculated Spearman rank 
medRxiv preprint doi: https://doi.org/10.1101/2020.12.28.20248193; this version posted July 22, 2021. The copyright holder for this preprint (which was not certified by peer review) is the author/funder, who has granted medRxiv a license to display the preprint in perpetuity.

It is made available under a CC-BY-NC-ND 4.0 International license .

639 correlation coefficients for the following two pairs of data: between top-10 accuracy

640 and the syndrome's distinctiveness score, and between top-10 accuracy and the

641 prevalence of syndromes collected from Orphanet.

642 The same analysis was also performed on the GMDB dataset. We selected 20

643 syndromes from GMDB frequent instead of 50 syndromes because the GMDB dataset

644 is smaller than the Face2Gene dataset, and we trained the Enc-GMDB-exclude-20 on

645 the remaining 119 frequent syndromes. The details of the 20 selected syndromes and

646 the results are reported in Supplementary Table 7. Please note that we report the top-

6475 accuracy in the GMDB dataset instead of top-10 accuracy because of the smaller

648 number of syndromes in the gallery.

\section{Analysis of number of training syndromes and subjects}

650 In this analysis, we evaluated the influence of training with additional syndromes and

651 subjects to the novel disorders. To avoid an imbalance among the syndromes, we used

652 the same number of subjects for each syndrome. We first used four different settings

653 for the number of subjects: $10,20,40$, and 80 . However, not all syndromes have the

654 four numbers of subjects we mentioned above for training: for $10,20,40$, and 80 655 subjects, there are $242,156,84$, and 40 syndromes. We then defined the ordering of 656 syndromes we added each time. To add the same syndromes for the four numbers of 657 subjects each time, we first sorted syndromes with the number of subjects in 658 descending order. To avoid bias due to having specific disorders added at each position, 659 we then performed random sorting five times within each of the intervals [1:40], [41, $66080]$, [81, 150], and [151, 240] to generate five different lists of syndromes. Thus, the 661 ordering from common disorders to rare disorders was by interval rather than by 662 syndrome. For example, Kabuki syndrome might be in the $9^{\text {th }}$ position in the first list, 663 but in the $20^{\text {th }}$ position in the second list, but in each randomly sorted list Kabuki 664 syndrome is in the first interval. 
medRxiv preprint doi: https://doi.org/10.1101/2020.12.28.20248193; this version posted July 22, 2021. The copyright holder for this preprint (which was not certified by peer review) is the author/funder, who has granted medRxiv a license to display the preprint in perpetuity.

It is made available under a CC-BY-NC-ND 4.0 International license .

665 For each of five different lists of training syndromes, we performed the same training

666 described as follows. We first trained $\mathrm{X}$ number of syndromes with ten subjects, where $667 X=10$ to 240 , incremented at an interval of ten syndromes. As mentioned above, there 668 are only 156 syndromes with more than 20 subjects. Thus, we trained syndromes with 66920 subjects with $X=10$ to 150 syndromes with the same increment of ten syndromes. 670 We performed the same process for 40 and 80 subjects, with maximums of 80 and 40 , 671 respectively.

672 For each setting (number of subjects, number of syndromes), we had five models. We 673 then encoded the photos separately with each model and tested them on the rare 674 syndromes, which had not been seen by the models. In the end, we averaged the 675 performance by the five models and report the top-10 accuracy for each setting in 676 Figure 3. We also used the models described above to encode the GMDB dataset, 677 tested them with the GMDB rare set, and report the results in Supplementary Figure 2.

678 Because the GMDB dataset is smaller than Face2Gene dataset, we were not able to 679 use the same number of subjects and syndromes to perform the analysis. For the 680 GMDB dataset, we used 10, 20, 40 for the number of subjects, and the syndrome 681 intervals of $[1,10],[11,40]$, and $[41,80]$. The results of training on GMDB and testing 682 of the GMDB rare set are shown in Supplementary Figure 3.

683 We next wanted to compare two scenarios, double the number of training syndromes 684 and double the number of training subjects. For example, we first set training on ten 685 subjects for each of ten syndromes as the base setting, then compared this 686 performance to training ten subjects for each of 20 syndromes (double syndromes) 687 and training 20 subjects for each of ten syndromes (double subjects). The base setting 688 had 100 subjects in total. Double syndromes and double subjects each had 200 689 subjects. This comparison allows us to understand the different influence of adding 
medRxiv preprint doi: https://doi.org/10.1101/2020.12.28.20248193; this version posted July 22, 2021. The copyright holder for this preprint (which was not certified by peer review) is the author/funder, who has granted medRxiv a license to display the preprint in perpetuity.

It is made available under a CC-BY-NC-ND 4.0 International license .

690 more syndromes and adding more subjects. The results are shown in Supplementary

691 Figures 4-6.

\section{Analysis of number of training syndromes in real-world scenario}

693 In this analysis, we trained the encoders with different numbers of syndromes to

694 simulate the real-world scenario. The difference to the previous section is that we used

695 all available subjects with each syndrome for the training. To make a fair comparison,

696 we first used the same ordering of syndromes as in the previous section, and we added

697 a fifth interval of $[241,299]$. For each of the five lists of syndromes, we then trained 16

698 encoders, each with a different number of training syndromes. The interval of

699 syndromes was 20 in this analysis due to the long training time. For example, we used

700 the first ten syndromes in the training list for the first encoder. For the second encoder,

701 we trained on the first 30 syndromes, and continually increased the number of

702 syndromes for each subsequent encoder by 20 until we reached 299 syndromes. Thus,

703 we simulated how syndromes would be included in model training in the real world. We

704 took the rare syndromes as the test set. We then averaged the performance of five

705 models with the same number of training syndromes and report the top-10 accuracy in

706 Supplementary Figure 7. 
medRxiv preprint doi: https://doi.org/10.1101/2020.12.28.20248193; this version posted July 22, 2021. The copyright holder for this preprint (which was not certified by peer review) is the author/funder, who has granted medRxiv a license to display the preprint in perpetuity.

It is made available under a CC-BY-NC-ND 4.0 International license .

Figures and tables

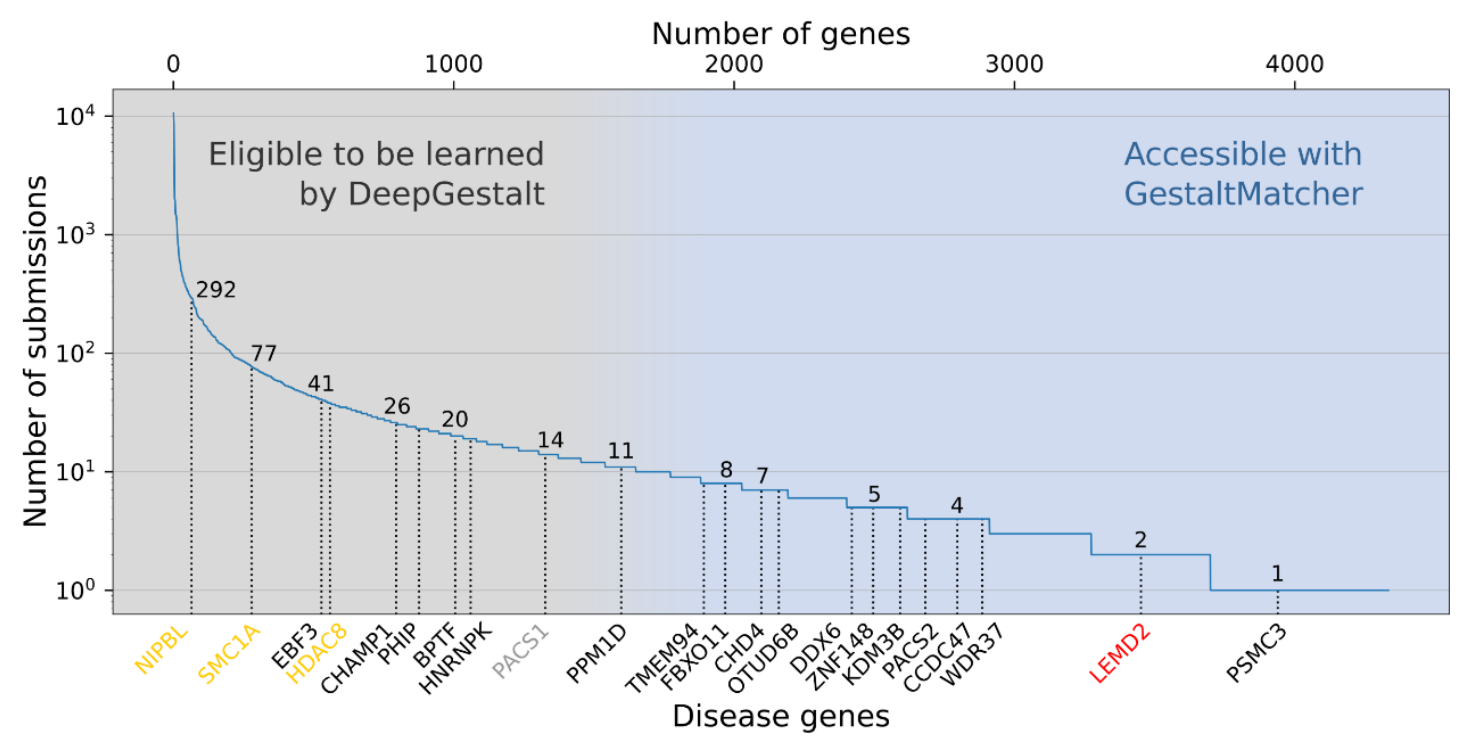

710 Figure 1: Subsets of disorders supported by DeepGestalt and GestaltMatcher.

711 The lower $x$-axis shows examples of disease genes, and the upper $x$-axis is the

712 cumulative number of genes. The y-axis shows the number of pathogenic submissions

713 in ClinVar for each gene. The numbers on the curve indicate the number of 714 submissions for each of the indicated genes. Most of the rare disorders that 715 DeepGestalt supports have relatively high prevalence based on their ClinVar 716 submissions, e.g. Cornelia de Lange syndrome (CdLS) which is caused by mutation in 717 NIPBL, SMC1A, or HDAC8, among other genes. Disease genes such as PACS1 cause 718 highly distinctive phenotypes but are ultra-rare, representing the limit of what current 719 technology can achieve. The first novel disease that was characterized by 720 GestaltMatcher is caused by mutations in LEMD2. A candidate disease gene 721 associated with a characteristic phenotype that can be identified by GestaltMatcher is 722 PSMC3. 
medRxiv preprint doi: https://doi.org/10.1101/2020.12.28.20248193; this version posted July 22, 2021. The copyright holder for this preprint (which was not certified by peer review) is the author/funder, who has granted medRxiv a license to display the preprint in perpetuity.

It is made available under a CC-BY-NC-ND 4.0 International license .

a

Deep Convolutional Neural Network

(1)
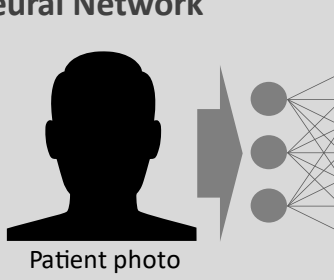

CONV-1 Feature encoder Fully

\section{Classifier}

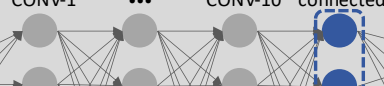

b

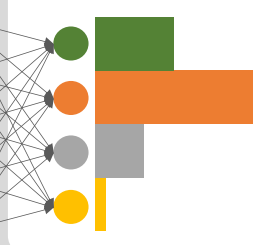

Coffin-Siris syndrome

Hutchinson-Gilford

Progeria syndrome (HGPS)

Schuurs-Hoeijmakers

syndrome (SHS)

Cornelia-de-Lange

syndrome (CdLS)

Clinical Face

Phenotype Space

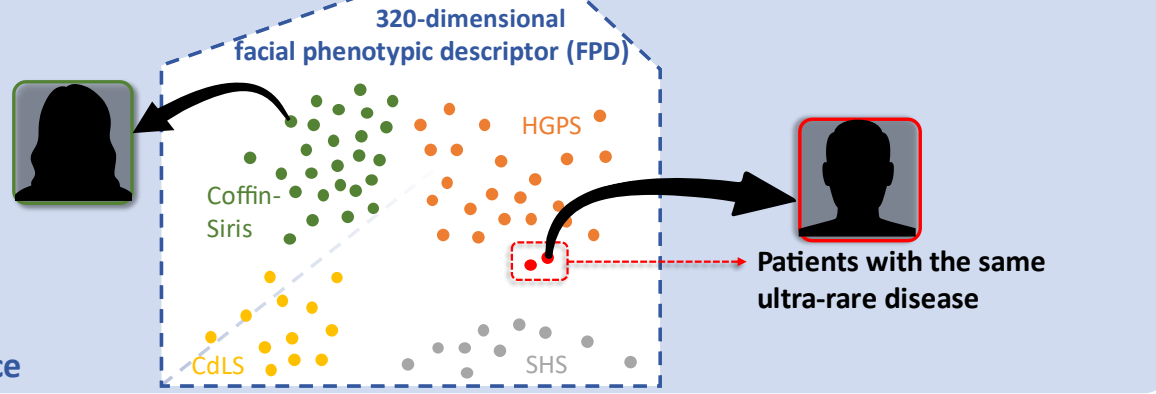

Figure 2: Concept of GestaltMatcher. a, Architecture of a deep convolutional neural

network (DCNN) consisting of an encoder and a classifier. Facial dysmorphic features of 299 frequent syndromes were used for supervised learning. The last fully connected layer in the feature encoder was taken as a Facial Phenotypic Descriptor (FPD), which forms a point in the Clinical Face Phenotype Space (CFPS). b, In the CFPS, the distance between each patient's FPD can be considered as a measure of similarity of their facial phenotypic features. The distances can be further used for classifying ultra-

731 rare disorders or matching patients with novel phenotypes. Take the input image as an 732 example: the patient's ultra-rare disease, which is caused by mutations in LEMD2, was 733 not in the classifier, but was matched with another patient with the same ultra-rare disorder in the CFPS ${ }^{4}$. 
medRxiv preprint doi: https://doi.org/10.1101/2020.12.28.20248193; this version posted July 22, 2021. The copyright holder for this preprint (which was not certified by peer review) is the author/funder, who has granted medRxiv a license to display the preprint in perpetuity. It is made available under a CC-BY-NC-ND 4.0 International license .

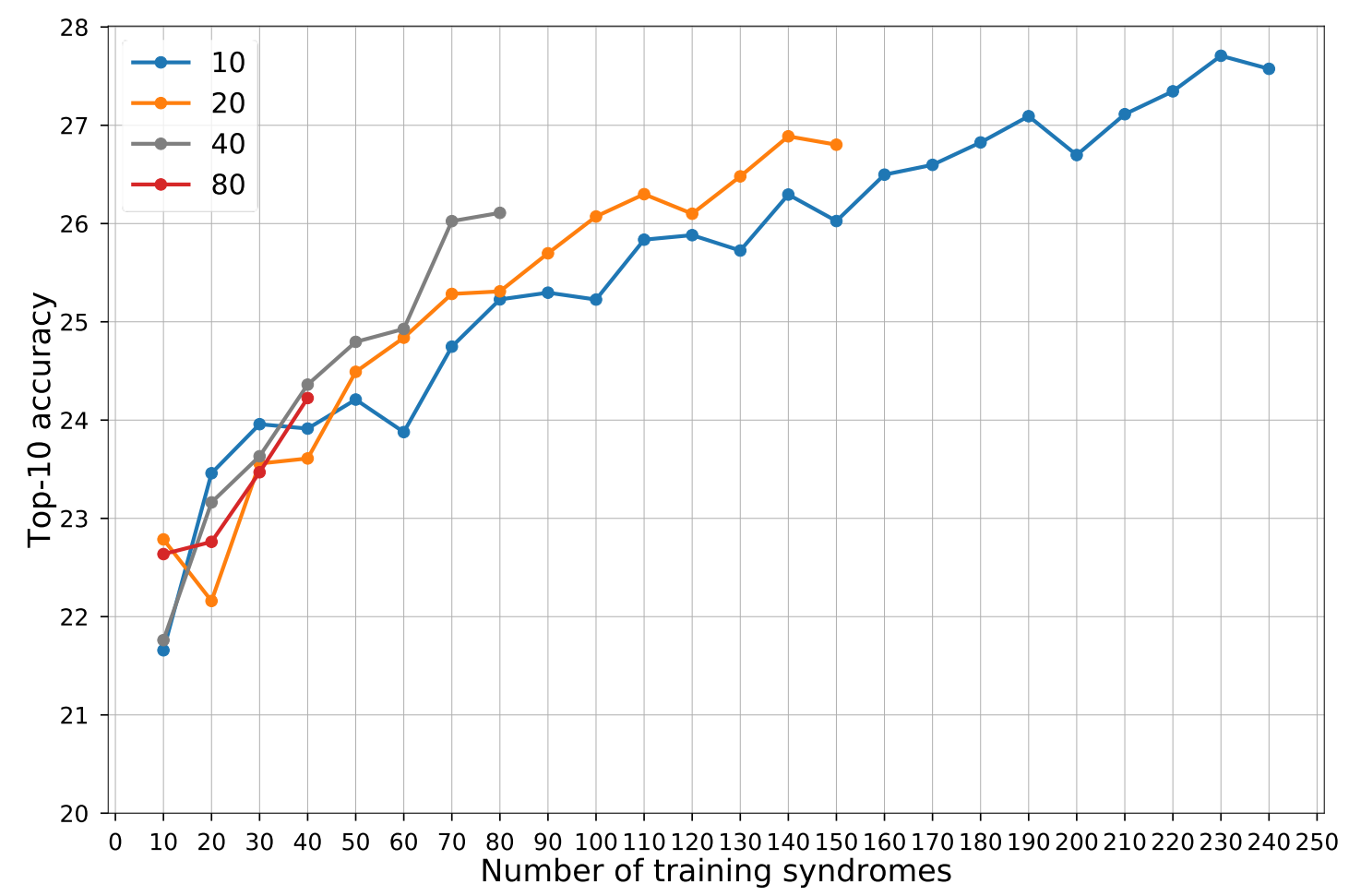

736 Figure 3: Influence of the number of syndromes included in model training. The

$737 \mathrm{x}$-axis is the number of syndromes used in model training. The $y$-axis shows the 738 average top-10 accuracy of testing on the rare set. Each line uses the same number 739 of subjects per syndrome, which is shown in the key. For each point, we train the 740 models five times with five different splits, and average the results. The null accuracy 741 (the expected value if the encoder returned random predictions) is $1.2 \%(10 / 816)$. 


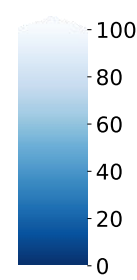

\section{TMEM94 pairwise rank}
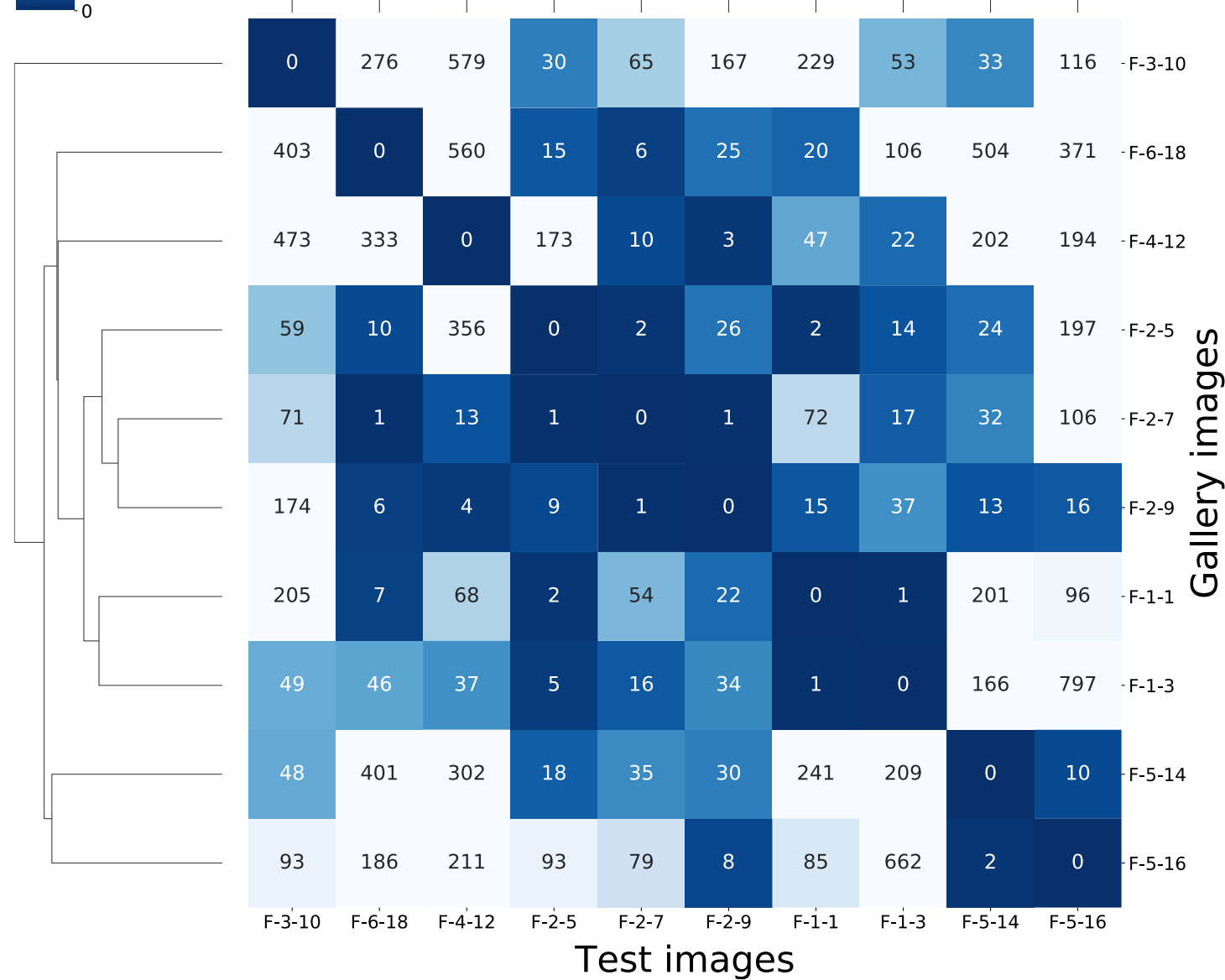

743 Figure 4: Pairwise ranks of subjects with mutations in TMEM94. Each label

744 consists of family numbering and subject numbering, which are the same as in the

745 original publication ${ }^{22}$. For example, F-2-7 means the seventh subject in the second

746 family. Each column is the result of testing the image indicated at the bottom of the

747 column. The number in the box is the rank to the corresponding image in the gallery.

748 The fourth column starting from the left is the result of testing F-2-5, and the fourth row

749 from the bottom shows that $\mathrm{F}-1-1$ has a rank of 2 for $\mathrm{F}-2-5$. In the fifth to seventh rows

750 from the bottom are the ranks from family 2 , which is the same family that F-2-5 is from. 
medRxiv preprint doi: https://doi.org/10.1101/2020.12.28.20248193; this version posted July 22, 2021. The copyright holder for this preprint (which was not certified by peer review) is the author/funder, who has granted medRxiv a license to display the preprint in perpetuity.

It is made available under a CC-BY-NC-ND 4.0 International license.

a

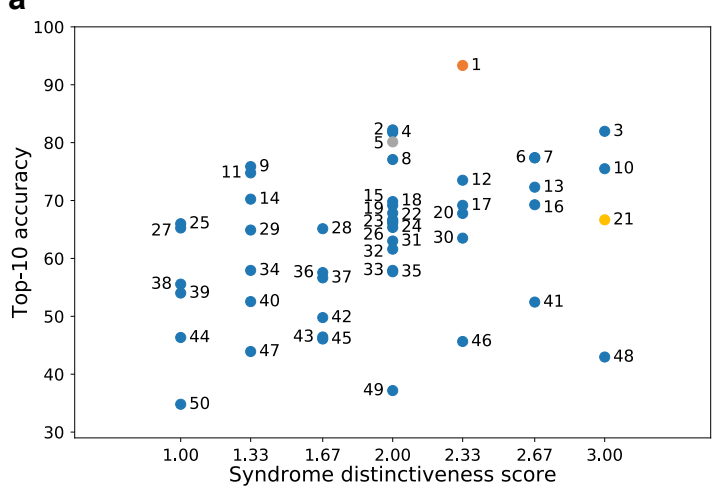

b

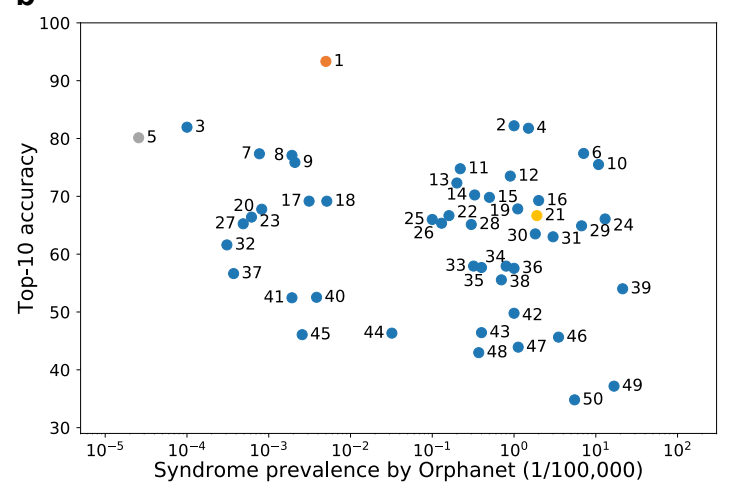

752 Figure 5: Correlation among syndrome prevalence, distinctiveness score, and

753 top-10 accuracy. a, Distribution of top-10 accuracy and distinctiveness score. The

754 Spearman rank correlation coefficient was $0.400(P=0.004)$. b. Distribution of top-10

755 accuracy and prevalence. The Spearman rank correlation coefficient was $-0.217(P=$

756 0.130) The details of each syndrome can be found in Supplementary Table 6 using the

757 syndrome ID shown in the figure; syndrome 5 is Schuurs-Hoeijmakers syndrome. The

$758 y$-axis shows the average top-10 accuracy of the experiments over 100 iterations. 
medRxiv preprint doi: https://doi.org/10.1101/2020.12.28.20248193; this version posted July 22,2021 . The copyright holder for this preprint (which was not certified by peer review) is the author/funder, who has granted medRxiv a license to display the preprint in perpetuity. It is made available under a CC-BY-NC-ND 4.0 International license .

760 Table 1: Performance comparison between classification and clustering with

761 different encoders on sets of known disorders.

\begin{tabular}{|c|c|c|c|c|c|c|c|c|c|}
\hline \multirow{2}{*}{ Test set } & \multirow{2}{*}{ Model } & \multicolumn{2}{|c|}{ Images } & \multirow{2}{*}{$\begin{array}{l}\text { Supported } \\
\text { syndromes }\end{array}$} & \multirow{2}{*}{$\begin{array}{l}\text { Null top-1 } \\
\text { accuracy }\end{array}$} & \multirow{2}{*}{ Top-1 } & \multirow{2}{*}{ Top-5 } & \multirow{2}{*}{ Top-10 } & \multirow{2}{*}{ Top-30 } \\
\hline & & Gallery & Test & & & & & & \\
\hline F2G-frequent & Enc-F2G (softmax) & - & 2,669 & 299 & $0.33 \%$ & $35.94 \%$ & $52.45 \%$ & $63.91 \%$ & $78.13 \%$ \\
\hline F2G-frequent & Enc-F2G & 19,950 & 2,669 & 299 & $0.33 \%$ & $21.06 \%$ & $39.62 \%$ & $49.12 \%$ & $67.98 \%$ \\
\hline F2G-frequent & Enc-healthy & 19,950 & 2,669 & 299 & $0.33 \%$ & $10.69 \%$ & $23.69 \%$ & $31.46 \%$ & $50.80 \%$ \\
\hline F2G-rare & Enc-F2G & $2,348.8$ & $1,183.3$ & 816 & $0.12 \%$ & $13.66 \%$ & $23.62 \%$ & $29.56 \%$ & $40.94 \%$ \\
\hline F2G-rare & Enc-healthy & $2,348.8$ & $1,183.3$ & 816 & $0.12 \%$ & $9.46 \%$ & $16.87 \%$ & $21.77 \%$ & $31.77 \%$ \\
\hline F2G-frequent & Enc-F2G & $22,298^{a}$ & 2,669 & $1,115^{c}$ & $0.09 \%$ & $20.15 \%$ & $37.81 \%$ & $46.85 \%$ & $64.21 \%$ \\
\hline F2G-frequent & Enc-healthy & $22,298^{a}$ & 2,669 & $1,115^{c}$ & $0.09 \%$ & $9.70 \%$ & $22.51 \%$ & $29.80 \%$ & $48.24 \%$ \\
\hline F2G-rare & Enc-F2G & $22,298.8^{b}$ & $1,183.3$ & $1,115^{c}$ & $0.09 \%$ & $7.07 \%$ & $14.19 \%$ & $17.67 \%$ & $24.41 \%$ \\
\hline F2G-rare & Enc-healthy & $22,298.8^{b}$ & $1,183.3$ & $1,115^{\mathrm{c}}$ & $0.09 \%$ & $4.02 \%$ & $8.84 \%$ & $11.73 \%$ & $16.61 \%$ \\
\hline
\end{tabular}

762 The DCNNs of Enc-F2G (softmax), Enc-F2G, and Enc-healthy have the same architecture.

763 Enc-F2G (softmax) and Enc-F2G training were initiated with CASIA-WebFace and further fine-

764 tuned on photos of patients in the Face2Gene frequent set. The Enc-F2G (softmax) model is

765 the same as Enc-F2G, but using the softmax values of the layer instead of cosine distances

766 between the FPDs in the CFPS. For the top-1 to top-30 columns, the best performance in each

767 set is boldfaced. The numbers of images and syndromes in the rare set are averaged over ten

768 splits. Enc-F2G outperformed Enc-healthy on both types of syndromes, showing the importance

769 of fine-tuning on patient photos for learning facial dysmorphic features. The top-10 accuracy of

770 Enc-F2G only drops by 2.27 percentage points after increasing the number of cases in the

771 gallery and almost quadrupling the number of supported syndromes from 299 to 1,115 .

$772{ }^{a}$ Number of images in frequent gallery and rare gallery.

$773{ }^{\mathrm{b}}$ Average of ten splits in the frequent gallery and rare gallery.

774 c Number of syndromes in the frequent gallery and rare gallery. 
medRxiv preprint doi: https://doi.org/10.1101/2020.12.28.20248193; this version posted July 22, 2021. The copyright holder for this preprint (which was not certified by peer review) is the author/funder, who has granted medRxiv a license to display the preprint in perpetuity.

It is made available under a CC-BY-NC-ND 4.0 International license .

776 Table 2: Matching of novel phenotypes on a GeneMatcher validation set.

\begin{tabular}{|c|c|c|c|c|}
\hline \multirow{2}{*}{ Gene } & \multirow{2}{*}{ PMID } & \multirow{2}{*}{$\begin{array}{c}\text { Total families } \\
\text { (Subjects) }\end{array}$} & \multicolumn{2}{|c|}{ Connected families (subjects) ${ }^{a}$} \\
\hline & & & Top-10 & Top-30 \\
\hline BPTF 32 & 28942966 & $6(6)$ & $0(0)$ & $2(2)$ \\
\hline$C C D C 47^{33}$ & 30401460 & $4(4)$ & $0(0)$ & $0(0)$ \\
\hline CHAMP $1^{34}$ & 27148580 & $4(4)$ & $2(2)$ & $4(4)$ \\
\hline $\mathrm{CHD} 4^{35}$ & 27616479 & $3(3)$ & $0(0)$ & $0(0)$ \\
\hline$D D \times 6^{36}$ & 31422817 & $4(4)$ & $4(4)$ & $4(4)$ \\
\hline$E B F 3^{37}$ & 28017373 & $6(7)$ & $0(0)$ & $0(0)$ \\
\hline$F B X 011^{38}$ & 30679813 & $17(17)$ & $5(5)$ & $9(9)$ \\
\hline HNRNPK ${ }^{39}$ & 26173930 & $3(3)$ & $3(3)$ & $3(3)$ \\
\hline$K D M 3 B^{40}$ & 30929739 & $9(9)$ & $0(0)$ & $2(3)$ \\
\hline$L_{E M D 2^{4}}$ & 30905398 & $2(2)$ & $2(2)$ & $2(2)$ \\
\hline OTUD6B ${ }^{41}$ & 28343629 & $4(9)$ & $3(4)$ & $3(6)$ \\
\hline$P A C S 2^{42}$ & 29656858 & $6(6)$ & $0(0)$ & $2(2)$ \\
\hline TMEM9422 & 30526868 & $6(10)$ & $5(8)$ & $6(10)$ \\
\hline WDR3743 & 31327508 & $4(4)$ & $2(2)$ & $3(3)$ \\
\hline ZNF14844 & 27964749 & $3(3)$ & $0(0)$ & $0(0)$ \\
\hline Total & - & $79(91)$ & $26(30)$ & $40(48)$ \\
\hline Average & - & - & $32.91 \%(32.97 \%)$ & $50.63 \%(52.75 \%)$ \\
\hline
\end{tabular}

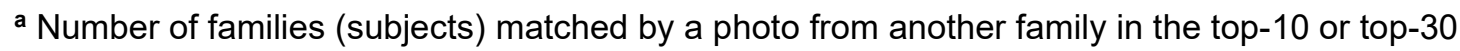

778 rank.

779 In the discovery mode for novel phenotypes, all cases in the gallery are without diagnosis. For 780 the performance readout, only the correct disease gene of a match is revealed. For individuals 781 of the TMEM94 study, e.g. eight out of ten subjects had an image from another family within 782 the top-10 rank, and five of the six families had at least one subject from another family in their 783 top-10 rank. For top-30 all subjects and families matched. This table is based on the ranks from 784 the similarity matrices in Figure 4 and Supplementary Figure 8. The accuracy of connected 785 subjects corresponds to the accuracy of using Enc-F2G on the F2G-rare test set in the Table 1 786 in discovery mode in the gallery of almost the same size. 
medRxiv preprint doi: https://doi.org/10.1101/2020.12.28.20248193; this version posted July 22, 2021. The copyright holder for this preprint (which was not certified by peer review) is the author/funder, who has granted medRxiv a license to display the preprint in perpetuity.

\section{References}

789 1. Ferreira, C. R. The burden of rare diseases. Am. J. Med. Genet. A 179, 885-892 (2019).

2. Baird, P. A., Anderson, T. W., Newcombe, H. B. \& Lowry, R. B. Genetic disorders in children and young adults: A population study. Am. J. Hum. Genet. 42, 677693 (1988).

3. Hart, T. C. \& Hart, P. S. Genetic studies of craniofacial anomalies: clinical implications and applications. Orthod. Craniofac. Res. 12, 212-220 (2009).

4. Marbach, F. et al. The Discovery of a LEMD2-Associated Nuclear Envelopathy with Early Progeroid Appearance Suggests Advanced Applications for Al-Driven Facial Phenotyping. Am. J. Hum. Genet. 104, 749-757 (2019).

5. Ferry, Q. et al. Diagnostically relevant facial gestalt information from ordinary photos. Elife 3, e02020 (2014).

6. Kuru, K., Niranjan, M., Tunca, Y., Osvank, E. \& Azim, T. Biomedical visual data analysis to build an intelligent diagnostic decision support system in medical genetics. Artif. Intell. Med. 62, 105-118 (2014).

7. Cerrolaza, J. J. et al. Identification of dysmorphic syndromes using landmarkspecific local texture descriptors. in 2016 IEEE 13th International Symposium on

8. Wang, K. \& Luo, J. Detecting Visually Observable Disease Symptoms from Faces. EURASIP J. Bioinform. Syst. Biol. 2016, 13 (2016).

9. Dudding-Byth, T. et al. Computer face-matching technology using twodimensional photographs accurately matches the facial gestalt of unrelated individuals with the same syndromic form of intellectual disability. BMC Biotechnol.

813 10. Shukla, P., Gupta, T., Saini, A., Singh, P. \& Balasubramanian, R. A Deep Learning Frame-Work for Recognizing Developmental Disorders. in 2017 IEEE Winter 
medRxiv preprint doi: https://doi.org/10.1101/2020.12.28.20248193; this version posted July 22, 2021. The copyright holder for this preprint (which was not certified by peer review) is the author/funder, who has granted medRxiv a license to display the preprint in perpetuity.

It is made available under a CC-BY-NC-ND 4.0 International license .

Conference on Applications of Computer Vision (WACV) 705-714 (2017).

11. Liehr, T. et al. Next generation phenotyping in Emanuel and Pallister-Killian syndrome using computer-aided facial dysmorphology analysis of 2D photos. Clin. Genet. 93, 378-381 (2018).

12. Gurovich, Y. et al. Identifying facial phenotypes of genetic disorders using deep learning. Nature Medicine vol. 25 60-64 (2019).

13. van der Donk, R. et al. Next-generation phenotyping using computer vision

14. Taigman, Y., Yang, M., Ranzato, M. \& Wolf, L. DeepFace: Closing the gap to human-level performance in face verification. in Proceedings of the IEEE Computer Society Conference on Computer Vision and Pattern Recognition 1701-1708 (IEEE Computer Society, 2014).

15. Huang, G. B., Ramesh, M., Berg, T. \& Learned-Miller, E. Labeled Faces in the Wild: A Database for Studying Face Recognition in Unconstrained Environments. http://vis-www.cs.umass.edu/lfw/.

16. Pantel, J. T. et al. Advances in computer-assisted syndrome recognition by the example of inborn errors of metabolism. J. Inherit. Metab. Dis. (2018)

17. Landrum, M. J. et al. ClinVar: improving access to variant interpretations and supporting evidence. Nucleic Acids Res.

46, D1062-D1067 (2018).

18. McKusick, V. A. On lumpers and splitters, or the nosology of genetic disease. Perspect. Biol. Med. 12, 298-312 (1969).

19. Yi, D., Lei, Z., Liao, S. \& Li, S. Z. Learning Face Representation from Scratch. (2014).

20. Winter, R. M. \& Baraitser, M. The London Dysmorphology Database. J. Med. Genet. 24, 509-510 (1987). 
medRxiv preprint doi: https://doi.org/10.1101/2020.12.28.20248193; this version posted July 22,2021 . The copyright holder for this preprint

(which was not certified by peer review) is the author/funder, who has granted medRxiv a license to display the preprint in perpetuity.

It is made available under a CC-BY-NC-ND 4.0 International license .

Tool for Connecting Investigators with an Interest in the Same Gene. Hum. Mutat. 36, 928-930 (2015).

22. Stephen, J. et al. Bi-allelic TMEM94 Truncating Variants Are Associated with Neurodevelopmental Delay, Congenital Heart Defects, and Distinct Facial Dysmorphism. Am. J. Hum. Genet. 103, 948-967 (2018).

23. Alvi, M., Zisserman, A. \& Nellåker, C. Turning a blind eye: Explicit removal of biases and variation from deep neural network embeddings. Lect. Notes Comput. Sci. 11129 LNCS, 556-572 (2019).

24. Lumaka, A. et al. Facial dysmorphism is influenced by ethnic background of the patient and of the evaluator. Clin. Genet. 92, 166-171 (2017).

25. Schuurs-Hoeijmakers, J. H. M. et al. Recurrent de novo mutations in PACS1 cause defective cranial-neural-crest migration and define a recognizable intellectual-disability syndrome. Am. J. Hum. Genet. 91, 1122-1127 (2012).

26. van der Maaten, L. \& Hinton, G. Visualizing Data using t-SNE. J. Mach. Learn. Res. 9, 2579-2605 (2008).

27. Rousseeuw, P. J. Silhouettes: a graphical aid to the interpretation and validation of cluster analysis. J. Comput. Appl. Math. 20, 53-65 (1987).

28. Richards, S. et al. Standards and guidelines for the interpretation of sequence variants: A joint consensus recommendation of the American College of Medical Genetics and Genomics and the Association for Molecular Pathology. Genet. Med. 17, 405-424 (2015).

29. Tavtigian, S. V. et al. Modeling the ACMG/AMP variant classification guidelines as a Bayesian classification framework. Genet. Med. 20, 1054-1060 (2018).

30. Philippakis, A. A. et al. The Matchmaker Exchange: A Platform for Rare Disease Gene Discovery. Hum. Mutat. 36, 915-921 (2015).

31. Nguengang Wakap, S. et al. Estimating cumulative point prevalence of rare diseases: analysis of the Orphanet database. Eur. J. Hum. Genet. 28, 165-173 (2020). 
medRxiv preprint doi: https://doi.org/10.1101/2020.12.28.20248193; this version posted July 22, 2021. The copyright holder for this preprint (which was not certified by peer review) is the author/funder, who has granted medRxiv a license to display the preprint in perpetuity.

It is made available under a CC-BY-NC-ND 4.0 International license.

871 32. Stankiewicz, P. et al. Haploinsufficiency of the Chromatin Remodeler BPTF

872 Causes Syndromic Developmental and Speech Delay, Postnatal Microcephaly, 873 and Dysmorphic Features. Am. J. Hum. Genet. 101, 503-515 (2017).

874 33. Morimoto, M. et al. Bi-allelic CCDC47 Variants Cause a Disorder Characterized by Woolly Hair, Liver Dysfunction, Dysmorphic Features, and Global Developmental Delay. Am. J. Hum. Genet. 103, 794-807 (2018).

34. Tanaka, A. J. et al. De novo pathogenic variants in CHAMP1 are associated with global developmental delay, intellectual disability, and dysmorphic facial features. Cold Spring Harb Mol Case Stud 2, a000661 (2016).

35. Weiss, K. et al. De Novo Mutations in CHD4, an ATP-Dependent Chromatin Remodeler Gene, Cause an Intellectual Disability Syndrome with Distinctive Dysmorphisms. Am. J. Hum. Genet. 99, 934-941 (2016).

36. Balak, C. et al. Rare De Novo Missense Variants in RNA Helicase DDX6 Cause Intellectual Disability and Dysmorphic Features and Lead to P-Body Defects and RNA Dysregulation. Am. J. Hum. Genet. 105, 509-525 (2019).

37. Harms, F. L. et al. Mutations in EBF3 Disturb Transcriptional Profiles and Cause Intellectual Disability, Ataxia, and Facial Dysmorphism. Am. J. Hum. Genet. 100,

38. Jansen, $\mathrm{S}$. et al. De novo variants in FBXO11 cause a syndromic form of intellectual disability with behavioral problems and dysmorphisms. Eur. J. Hum. Genet. 27, 738-746 (2019).

39. Au, P. Y. B. et al. GeneMatcher aids in the identification of a new malformation syndrome with intellectual disability, unique facial dysmorphisms, and skeletal and connective tissue abnormalities caused by de novo variants in HNRNPK. Hum. Mutat. 36, 1009-1014 (2015).

40. Diets, I. J. et al. De Novo and Inherited Pathogenic Variants in KDM3B Cause Intellectual Disability, Short Stature, and Facial Dysmorphism. Am. J. Hum. Genet. 104, 758-766 (2019). 
medRxiv preprint doi: https://doi.org/10.1101/2020.12.28.20248193; this version posted July 22, 2021. The copyright holder for this preprint

(which was not certified by peer review) is the author/funder, who has granted medRxiv a license to display the preprint in perpetuity.

It is made available under a CC-BY-NC-ND 4.0 International license .

899 41. Santiago-Sim, T. et al. Biallelic Variants in OTUD6B Cause an Intellectual 900 Disability Syndrome Associated with Seizures and Dysmorphic Features. Am. J. $901 \quad$ Hum. Genet. 100, 676-688 (2017).

902 42. Olson, H. E. et al. A Recurrent De Novo PACS2 Heterozygous Missense Variant Causes Neonatal-Onset Developmental Epileptic Encephalopathy, Facial Dysmorphism, and Cerebellar Dysgenesis. Am. J. Hum. Genet. 102, 995-1007

905 (2018).

906 43. Kanca, O. et al. De Novo Variants in WDR37 Are Associated with Epilepsy, Colobomas, Dysmorphism, Developmental Delay, Intellectual Disability, and Cerebellar Hypoplasia. Am. J. Hum. Genet. 105, 413-424 (2019).

44. Stevens, S. J. C. et al. Truncating de novo mutations in the Krüppel-type zincfinger gene ZNF148 in patients with corpus callosum defects, developmental delay, short stature, and dysmorphisms. Genome Med. 8, 131 (2016). 